\title{
Prospects for the use of extraordinary brick bond types
}

\author{
Evgeniy Pugach $^{1}$, and Alina Iumasheva ${ }^{1, *}$ \\ ${ }^{1}$ Moscow State University of Civil Engineering, 129337, Yaroslavskoe Shosse 26, Moscow, Russia
}

\begin{abstract}
The aim of this paper is to prove the applicability of extraordinary brick bond types in the same amount as traditional. Traditional brick bond type is a term describing the most widely used brick bonds which are almost all publications, manuals and textbooks in masonry craft are devoted to. And the most typical representatives reflecting the main trends in the development of the entire totality brick bond systems were selected as extraordinary ones. In total 16 systems were selected. The research methods used are obtaining the values of the basic constructional, technological and economic characteristics of the masonry (such as material consumption, labour input, compressive strength, maximum wall height, financial expenses) and following data analysis. The result obtained in the study confirmed that there is an equal possibility of using extraordinary bond systems as traditional ones because the value of basic characteristics in complex are more rational and more profitable compared with traditional. The research has practical importance because acquired information allows architects and engineers to choose the most optimal brick bond type to increase the efficiency of masonry.
\end{abstract}

\section{Introduction}

Masonry is one of the most widely used materials in construction industry. The most common component of masonry construction is a brick. A great economic effect will be produced by the discovery and application of rational methods for the brickwork constructional design. This rationalization can be achieved by many ways. A proper selection of the bonding type is one of them. The right choice will not only increase the masonry aesthetic appeal, but also improve its structural and technological properties.

Brick bond system is a certain arrangement of bricks relative to each other: bricks are fixed in a special composition vertically, as well as at lengthwise and crosswise directions of masonry structure. The behaviour of bricks in the masonry depends on the selected brick bond type and thereby determines general strength of the structure.

Brick bond systems began to develop along with the stone building craft advent. It originated more than 8000 years ago using sun -dried bricks made from the dirt. It is confirmed by the oldest brick found on the Jordan River banks [1]. The first structures which design was slightly look like modern ones appeared in Ancient Rome hundreds of years BC. At that time the Romans mastered the technology of masonry construction using

* Corresponding author: a.y.yumasheva@mail.ru 
burnt clay bricks and lime mortar. So masonry experience was gradually accumulated. This experience led to the appearance of the first principles of laying stones relative to each other. It was the prototype of modern brick bonding [2].

Over time the increasing needs of people required the construction of ever higher and heavier structures. People also wanted more qualitative constructions with less material investments. These needs were changing the relationship between market price and quality [3]. The search for their optimal ratio has begun: looking for masonry with better strength and decorative characteristics new brick bond types were invented.

The brick bond system developing was irregular all around the world because of climatic, political and economic reasons. For example, in Kievan Rus the first masonry construction was Church of the Tithes built in Kiev just in 10th century. It was made using the simplest bond type. Later Mongol invasion of Kievan Rus happened, that's why brickwork was no longer in use, and developing of bond systems was also stopped in Kievan Rus until reaching the independence in the middle of 15 th century. So while in Russia brick bonds were out of use, in England majestic brick castles were constructed using various brick bonds for every building.

Despite all the variety of brick bond types only a few of them are widely used now. For the vast majority of constructions the following systems are used the most: English, Flemish, Dutch, Gothic, Monk, Stretcher (offset by a half brick), Silesian and American (Fig. 1). In some regions, for example, in modern Russia, mainly only a few types of brick bond systems are used - English, Stretcher (offset by a half brick) and American. Such a narrow range originates in the USSR when the first priority in construction industry was accelerating the building process using established brick bond types. Also there was no need in original design. Other brick bond systems were fully ignored because carrying out researches on various brickwork technological and especially decorative properties was not relevant. As a result, due to the ignorance of the non-widespread brick bonds characteristics its application has become limited. In its turn, such restricted usage reduces the likelihood of their research and following improvement.

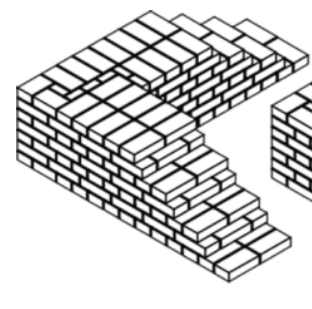

a)

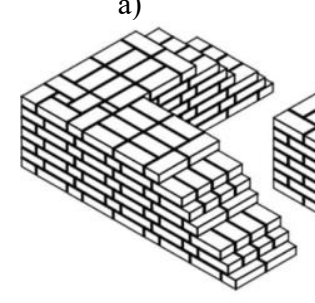

e)

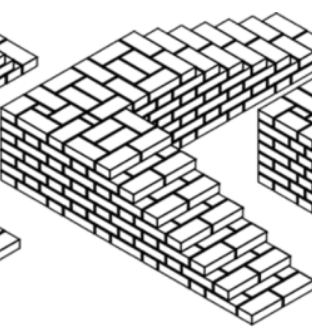

b)

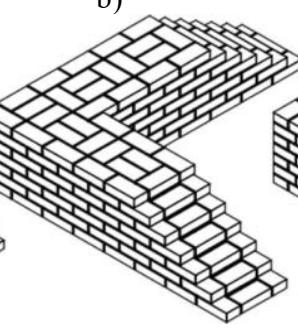

f)

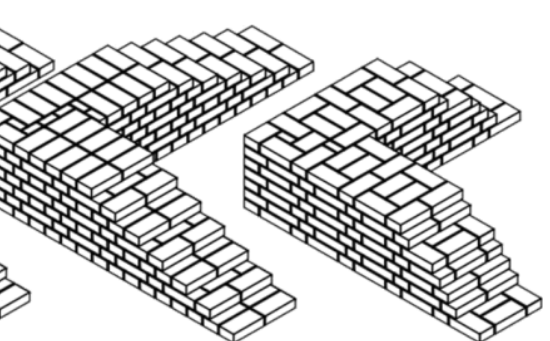

c)

d)

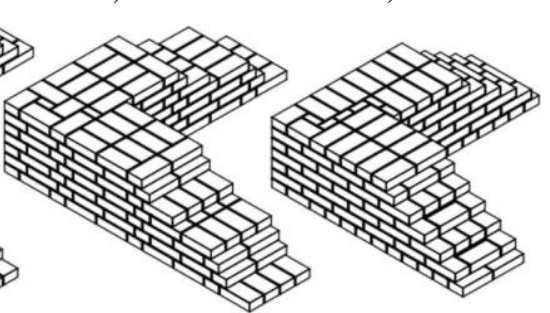

g)

h)

Fig. 1. The most popular types of brick bonds: $a$ - English; $b$ - Flemish; $c-$ Dutch; $d$ - Gothic; $\mathrm{e}-$ Monk; f - Stretcher (offset by a half brick); $\mathrm{g}$ - Silesian; $\mathrm{h}$ - American.

Also there is a geographical factor causing limiting the number of brick bond types in use. For example, in some towns of the USA in 20th century a wide variety of brick bond 
systems was applied in buildings [4], but it was not inherited by other countries because the location of those buildings was too far even just to know about their existing.

Today the needs and desires of people have increased significantly, so an urgency to find new methods to design masonry appeared. The use of classic brick bond types in some cases becomes ineffective. The relevance of this paper is caused by the need to obtain information about the extraordinary bond systems. The data obtained is required for wide practical use in the construction industry because its application minimizes the amount of all resources types and in the same time it improves the quality of masonry.

The aim of this paper is to prove the potentiality of applying extraordinary brick bond types in the same amount as traditional ones, and it should be based on constructional, technological and economic characteristics obtained during research. In this analysis brick bond types are applied to the loadbearing wall.

Existing literature on this topic is quite limited. There are only few researches on the same exact field [5], so there was an attempt to study the issue earlier. Almost all papers about brick bond types and its properties have the subject of study belonged to adjacent fields of knowledge, so researches don't contain exact information about bond systems characteristics. Thus, some articles pay more attention to the decorative aspect of brickwork raising the question about priority of the brickwork colour over the pattern made up from using certain bond system [6] or describing the principles of using a rectangle shape to design a harmonious masonry pattern [7]. Looking for unique façades that decorate buildings, researchers create articles on masonry made up from whole bricks, three-quarter closures, bats and quarter closures [8]. A vast majority of articles is devoted to the technical side of the issue, especially the shear resistance and cross breaking strength of bonds [9] and the influence of masonry geometry on the strength of uniaxial compression [10] are being studied. Also there are articles about applying brick bond systems in special conditions, for example, the effectiveness of the unbonded brickwork use in seismically active areas is considered [11]. Some publications consider masonry dressing systems that are obsolete and forgotten, for example, masonry without visible bonding bricks. The obsolete and forgotten brick bond types are paid attention to in some articles such as ones that do research on bond system without visible headers [12]. Thus, the analysis of existing literature leads to the conclusion about almost complete absence of researches accurately related to the issue of this paper.

\section{Materials and Methods}

For comparison in this paper 8 brick bond types were selected as extraordinary (Fig. 2). Some types are so rare to use that they do not have their own name, so for convenience, all systems are indicated by serial numbers from 1 to 8 .

Among the whole variety of brick bond systems, the most indicative ones were selected as extraordinary. The choice is based on the fact that selected system should accurately reflect the authentic features of the largest groups of similar brick bond patterns. For example, Type 1 is derived from the Dutch brick bond and reflects the method of forming a bond group by shifting rows horizontally relative to each other in the original system. This system was widely used back in the 16th century in Europe, but over time it lost its applicability and became only a part of the history concentrated in walls of medieval castles. Type 4 is derived from the English brick bond and reflects the method of forming a bond group by adding other types of bricks into the rows: in this bond additional headers are added to. Type 5 represents a big group of brick bonds which main special feature is obtaining a large diamond pattern on the wall surface. And Type 6 is related to the group of brick bonds which main special feature is obtaining a small diamond pattern on the wall surface. Such patterns were very popular in Europe in the middle of 19th century. 


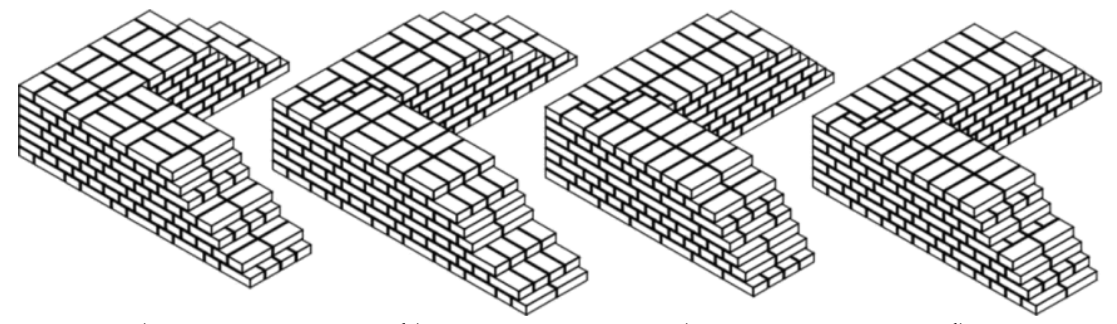

a)

b)

c)

d)

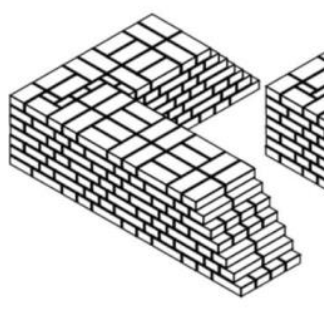

e) f)

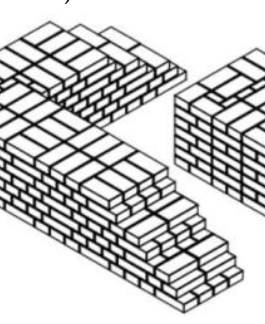

)

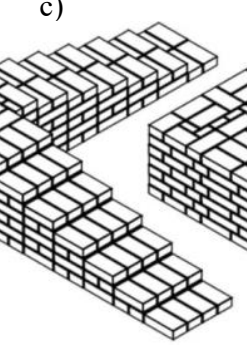

g)

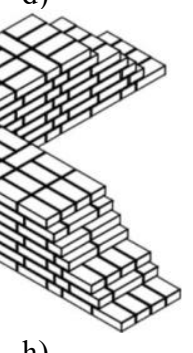

h)

Fig. 2. Extraordinary types of brick bonds: a - Type 1; b - Type 2; c - Type 3; d - Type 4; e - Type 5; f - Type 6; $\mathrm{g}$ - Type 7; h-Type 8 .

Optionally headers in these brick bond systems were brushed with black glossy paint to add more fanciness to the wall [13]. Type 7 represents a massive group of brick bond types with unbonded vertical joints. This group is called Stock brick bonds. As a representative was chosen namely this type because other brick bonds in this group are not fully acceptable for loadbearing walls. Type 7 is mainly used in façade constructions. Nowadays Stock brick bonds slowly gaining popularity but only in the field of low-rise private building. Type 8 reflects the feature of the category of brick bonds which is variation of expressive patterns made by stretchers offset in vertical rows by a third of their length relative to each other. This direction of brick bond systems development allows constructing curved structures [14].

Obviously presented bond systems don't fully performed all the variety of masonry bond types exiting in the world: there are numerous bond types and they are so different from each other that it is impossible to do research on all of them in the frame of one paper.

The brick bond systems under consideration include patterns with different rarity of use. One of them is absolutely uncommon and one of them is more popular to that point when its limited acceptance has brought its own name. So Type 2 is called French brick bond and Type 3 is called Double English Cross brick bond. Despite the fact that these systems have raised some popularity the preference is still usually given to more traditional brick bond types.

To ensure comparability of the comparison results it is necessary to set loadbearing wall structures of the same thickness: in the frame of this research all the thickness of constructions are $510 \mathrm{~mm}$ which corresponds to the thickness of wall made up from two bricks.

To carry out a comparison it is necessary to study all fundamental constructional, technological and economic characteristics of brickwork using previously defined brick bond types. Only the most basic parameters are considered which limit the possibility of using bond systems in the construction and directly influence on the final cost of $1 \mathrm{~m}^{3}$ of the brickwork.

A structure of the bricklaying gang in general is recommended to set depending on the complexity and thickness of the structure being constructed. The complexity is contingent on the presence of cornices, pilasters, pediments, etc. Since the wall structure described 
earlier has no complex parts and the thickness of wall is the same for all brick bond types, the structure of the bricklaying gang is identical for all cases and consists of three bricklayers: one has fourth labor grade, other one has third labor grade and the last one has second labor grade (according to the Russian classifier). The number of bricks laid by bricklayers of the third and fourth labor grade is $75 \%$ of the total, and for the bricklayer of the second labor grade works with the remaining $25 \%$.

The set of tools and equipment is also the same in all cases. It includes brick trowels, mortar mixing spades, brick hammers, perpendiculars, carpenter's levels, steel brick jointers, steel zigzag rules, duralumin leveling boards, angle pieces, mason line, tape rules, steel self-contained gauge rods, $0.27 \mathrm{~m}^{3}$ steel mortar boxes, water buckets. The number of tools matches the number of bricklayers.

In some circumstances it is necessary to change the size of brick. It can be done by cutting a stone into the required size and shape. Brick hammer, chipping chisel, jab saw, slicer machine and other tools are used to obtain a brick of necessary volume. Providing the construction process with appropriate equipment requests increased financial investments. And extra work as cutting bricks requires additional labour inputs. Pieces of stone are formed as a result of manipulating with bricks may not be suitable in size for further use in brickwork. It causes the fact that some part of the purchased material does not go into craft. In this way excess investments in buying a brick are produced. The considered brick bond types with an accepted design thickness of $510 \mathrm{~mm}$ exclude brick cutting. But if thickness of wall types with an accepted patterns is $380 \mathrm{~mm}$, then $63 \%$ of traditional and $50 \%$ of extra brick bond systems require manipulating with bricks which cut into two equal pieces. In this case the exceed of material is minimal since both parts of the stone can be used in masonry

The required amount of materials is determined per unit area of the wall and per unit volume of masonry. Brick consumption is represented both in cubic meters of bricks and in pieces per unit volume of masonry. The intake of mortar is calculated considering the condition that the thickness of the horizontal joints should be $12 \mathrm{~mm}$ and the thickness of the vertical joints should be $10 \mathrm{~mm}$. Nevertheless the value of the ideal thickness of the mortar joints is still at the research stage [15].

Labor inputs for the cubic meter of construction are measured for joints pointing brickwork. Russian norms (such as "Unified Norms and Prices. Volume 3. Masonry») contain the labor input values for the most common brick bond types (English and American) that are recommended to use while forming an organizational and technological documentation. The labor input value is affected by many factors. The largest aspects that impact the most are changing the direction of laying bricks in a row, abnormally offsetting bricks relative to each other or complete offset absence, the presence or absence of hearting in brick masonry.

There are several methods to lay brick for considered bond systems. Hearting stones are laid by lightly immersing in the mortar and moving to other bricks. Wythe bricks are laid in the same way but harder and with the help of brick trowel to form mortar joints. That's why the labour input values for both methods are not large.

Compressive strength of brickwork depends on the pressure distribution equability over the brick surface. There are Sets of Rules in Russia that regulate the brickwork compressive strength. These documents contain the compressive strength values of the most common brick bond types including systems with unbonded vertical joints. In this paper the value of compressive strength depends mainly on the brick location relative to each other since all structures in this paper are made of bricks and mortar of the same grades. The greater level of brick bonding, the greater a solidity of the structure which leads to the greater compressive strength value of masonry [16]. Lengthwise brick bonding is realized by 
laying header bricks. Crosswise brick bonding is realized by alternation header rows and stretcher rows offsetting adjacent rows by each other.

The maximum height of the masonry wall is limited by the stability of structure in the position of rest. If a vertical load approaching the value of the compressive strength of the masonry is applied to the wall, then it is the loss of stability in the rest position of the brick columns formed as a result of the brickwork disintegration that will precede the critical damage of the structure. The acceptable wall height in general depends on the wind region where construction is built and the thickness of the erected wall. In this paper all constructions are built in the equal geographical conditions and an influence of these factors is excluded. So selected brick bond system is only factor that impact the degree of wall stability in the rest. Each brick bond type has an individual level of bonding and it determines how fast the moment of brickwork disintegration into columns under load will come [17]. Variation of bonding systems causes different density of brickwork since the ratio of the brick consumption and the mortar consumption in each case is also different.

The analysis results of the various brick bond types are presented in tabular form (Tab. 1). This table does not contain characteristics which values are the same for all bond types.

Table 1. Constructional, technological and economic characteristics of loadbearing wall designed with different brick bond types.

\begin{tabular}{|c|c|c|c|c|c|}
\hline \multirow{2}{*}{$\begin{array}{c}\text { Brick bond } \\
\text { type }\end{array}$} & $\begin{array}{c}\text { Material consumption, } \\
\mathrm{m}^{3} / \mathrm{m}^{3} \text { of wall }\end{array}$ & $\begin{array}{c}\text { Labour input, } \\
\text { mhrs } / \mathrm{m}^{3}\end{array}$ & $\begin{array}{c}\text { Compressive } \\
\text { strength, MPa }\end{array}$ & $\begin{array}{c}\text { Maximum wall } \\
\text { height, } \mathrm{m}\end{array}$ \\
\cline { 2 - 6 } & Brick & Mortar & \multicolumn{5}{|c|}{ Traditional } \\
\hline English & 0.7768 & 0.223 & 3.20 & 3.20 & 4.2 \\
\hline Flemish & 0.7768 & 0.223 & 3.37 & 3.37 & 4.2 \\
\hline Dutch & 0.7768 & 0.223 & 3.25 & 3.25 & 4.2 \\
\hline Gothic & 0.7768 & 0.223 & 3.43 & 3.12 & 4.2 \\
\hline Monk & 0.7768 & 0.223 & 3.22 & 2.96 & 4.0 \\
\hline Stretcher & 0.7630 & 0.237 & 3.31 & 3.02 & 4.2 \\
\hline Silesian & 0.7768 & 0.223 & 3.31 & 2.88 & 4.0 \\
\hline American & 0.7946 & 0.206 & 3.20 & 3.00 & 4.2 \\
\hline \multicolumn{7}{|c|}{} & & Extraordinary & & 4.0 \\
\hline Type 1 & 0.810 & 0.190 & 3.25 & 3.31 & 4.1 \\
\hline Type 2 & 0.834 & 0.166 & 3.32 & 3.22 & 4.1 \\
\hline Type 3 & 0.801 & 0.199 & 3.28 & 3.08 & 4.2 \\
\hline Type 4 & 0.799 & 0.201 & 3.32 & 3.20 & 4.2 \\
\hline Type 5 & 0.810 & 0.190 & 3.35 & 3.15 & 4.1 \\
\hline Type 6 & 0.809 & 0.191 & 3.38 & 3.06 & 2.8 \\
\hline Type 7 & 0.832 & 0.168 & 3.02 & 2.59 & 4.1 \\
\hline Type 8 & 0.808 & 0.192 & 3.44 & 3.05 & \\
\hline
\end{tabular}

The data presented in Tab. 1 allows to conclude that for constructions designed with traditional brick bond types require less brick consumption (average number is $0.7773 \mathrm{~m}^{3}$ per $\mathrm{m}^{3}$ of wall) compared to extraordinary types (average number is $0.8129 \mathrm{~m}^{3}$ per $\mathrm{m}^{3}$ ). Typical bond systems require greater amount of mortar (average number is $0.223 \mathrm{~m}^{3}$ per $\mathrm{m} 3$ of wall versus $0.187 \mathrm{~m}^{3}$ per $\mathrm{m}^{3}$ of wall for extraordinary types). 
Labour inputs for cubic meter of brickwork by the average value are the same for both traditional and extraordinary brick bond types. It amounts to 3.29 man-hours per $\mathrm{m}^{3}$.

The average compressive strength of masonry designed with traditional brick bond types is $3.10 \mathrm{MPa}$ and for extraordinary types it amounts to $3.08 \mathrm{MPa}$. The difference is minimal and equals to $0.65 \%$.

The average value of the maximum wall height of masonry designed with traditional brick bond types is $4.15 \mathrm{~m}$ while for extraordinary types this parameter is reduced to 3.95 $\mathrm{m}$. The difference is $5 \%$.

\section{Results}

Data general analysis leads to the result that extraordinary brick bond types can be used along with the traditional ones: this fact is confirmed by obtained values of constructional and technological characteristics of loadbearing wall designed with different brick bond systems. The average compressive strength of masonry is almost the same for both traditional and extraordinary bond types. The maximum wall heights in all cases are equal to or higher than the usual floor height so all systems are suitable for practical use.

The use of extraordinary bond types is also economically justified. Labor inputs for the cubic meter of brickwork by the average value are the same. Traditional brick bond types require $19.25 \%$ more mortar consumption and extraordinary types require $4.58 \%$ more brick consumption. As of November 1, 2019, the price of $1 \mathrm{~m}^{3}$ of mortar in Russia is approximately $\$ 54$, and for brick is $\$ 78$. Then for traditional bond systems there is overpayment for the mortar in the amount of $\$ 1.94$ and for extraordinary bond systems there is overpayment for the brick in the amount of $\$ 2.78$. However, brick and mortar are usually purchased together, so the benefits of saving one type of material are offset by losses from the purchase of another type of material [18]. Total average price for the materials purchase for cubic meter of masonry designed with traditional bond types is $\$ 72.65$ and with extraordinary ones is $\$ 73.51$, which is $1.18 \%$ more.

Though in the case of all existing brick bond types separate analysis it turns out that each bond type has its own advantages and disadvantages since the values of every system characteristic is different from the average values for the group to which it belongs. The advantage is a value of parameter that improves the quality of the brickwork. And the disadvantage is a value of parameter that degrades the quality of the brickwork. To determine the advantages and disadvantages of every brick bond type it is necessary to consider each of these systems separately.

The results of comparing the parameters of each brick bond types individually with the obtained earlier average values of the parameters for the opposite group, taken as a standard, are given in Tab. 2. Deviation from the average value determines whether this bond system is individually worse or better compared to the opposite group of brick bond types.

The data presented in Tab. 2 allows to conclude that the low value of some brick bond types characteristics in the case of a difference from the average in the opposite group by a significant amount is compensated by a difference in other characteristic of the same brick bond type the value of which can be considered as an advantage for masonry.

The brick consumption value and the mortar consumption value are different for every brick bond system. Despite this fact the cost reduction or overpayments of money are equal in all cases. The average deviation of the cost difference in the required amount of bricks from the price of a cubic meter of brickwork is $\$ 2.775$ (or $3.56 \%$ ) for traditional types and $\$ 2.774$ (or $3.56 \%$ ) for extraordinary types. The average deviation of the cost difference in the required amount of mortar from the price of a cubic meter of brickwork is $\$ 1.92$ (or $3.56 \%$ ) for traditional types and $\$ 1.92$ (or 3.56\%) for extraordinary types. 
Table 2. Qualitative analysis of brick bond types

\begin{tabular}{|c|c|c|c|c|c|c|}
\hline \multirow{2}{*}{$\begin{array}{c}\text { Brick } \\
\text { bond type }\end{array}$} & \multicolumn{3}{|c|}{$\begin{array}{l}\text { Material consumption cost } \\
\text { reduction, USD }\end{array}$} & \multirow{2}{*}{$\begin{array}{c}\text { Labour input } \\
\text { difference, } \\
\text { mhrs } / \mathrm{m}^{3}\end{array}$} & \multirow{2}{*}{$\begin{array}{l}\text { Compressive } \\
\text { strength } \\
\text { difference, } \\
\mathrm{MPa}\end{array}$} & \multirow{2}{*}{$\begin{array}{c}\text { Maximum } \\
\text { wall height } \\
\text { difference, } \\
\mathrm{m}\end{array}$} \\
\hline & Brick & Mortar & Total & & & \\
\hline \multicolumn{7}{|c|}{ Traditional } \\
\hline English & 2.81 & -1.94 & 0.88 & $2.88 \%$ less & $3.81 \%$ more & $6.33 \%$ more \\
\hline Flemish & 2.81 & -1.94 & 0.88 & $2.28 \%$ less & $9.33 \%$ more & $6.33 \%$ more \\
\hline Dutch & 2.81 & -1.94 & 0.88 & $1.37 \%$ less & $5.43 \%$ more & $6.33 \%$ more \\
\hline Gothic & 2.81 & -1.94 & 0.88 & $4.10 \%$ more & $1.22 \%$ more & $6.33 \%$ more \\
\hline Monk & 2.81 & -1.94 & 0.88 & $2.28 \%$ less & $3.97 \%$ less & $1.27 \%$ more \\
\hline Stretcher & 3.89 & -2.69 & 1.20 & $0.46 \%$ more & $2.03 \%$ less & $6.33 \%$ more \\
\hline Silesian & 2.81 & -1.94 & 0.88 & $0.46 \%$ more & $6.57 \%$ less & $1.27 \%$ more \\
\hline American & 1.43 & -1.02 & 0.41 & $2.88 \%$ less & $2.68 \%$ less & $6.33 \%$ more \\
\hline \multicolumn{7}{|c|}{ Extraordinary } \\
\hline Type 1 & -2.55 & 1.76 & -0.79 & $1.10 \%$ less & $6.77 \%$ more & $3.61 \%$ less \\
\hline Type 2 & -4.42 & 3.06 & -1.36 & $1.03 \%$ more & $3.87 \%$ more & $1.20 \%$ less \\
\hline Type 3 & -1.85 & 1.28 & -0.57 & $0.19 \%$ less & $0.65 \%$ less & $1.20 \%$ less \\
\hline Type 4 & -1.69 & 1.17 & -0.52 & $1.03 \%$ more & $3.23 \%$ more & $1.20 \%$ more \\
\hline Type 5 & -2.55 & 1.76 & -0.79 & $1.94 \%$ more & $1.61 \%$ more & $1.20 \%$ more \\
\hline Type 6 & -2.47 & 1.71 & -0.76 & $2.85 \%$ more & $1.29 \%$ less & $1.20 \%$ less \\
\hline Type 7 & -4.27 & 2.95 & -1.32 & $8.10 \%$ less & $16.45 \%$ less & $32.53 \%$ less \\
\hline Type 8 & -2.39 & 1.65 & -0.74 & $4.68 \%$ more & $1.61 \%$ less & $1.20 \%$ less \\
\hline
\end{tabular}

Total cost reduction for the building materials purchase for traditional brick bond types compared to extraordinary ones is $\$ 0.86$ (or $1.17 \%$ of the cost of a cubic meter of masonry designed with extraordinary brick bonds types). Total cost reduction for the building materials purchase for extraordinary brick bond types compared to traditional ones is $\$ 0.86$ (or $1.18 \%$ of the cost of a cubic meter of masonry designed with traditional brick bonds types).

Also information obtained in Tab. 2 allows to conclude that despite the fact that some brick bond types have better characteristics than others, an ideal brick bond system for universal applying does not exist because same types in some cases can be unsuitable for construction for a number of other characteristics. Every brick bond type has its disadvantages and there is always another system which some characteristics are better but others characteristics are worse. Since it was earlier established that the deviations of the characteristics average values for traditional and extraordinary bond systems are insignificant in comparison with each other, the insignificant deviations of the systems from the parameters within each group on the scale of the whole group are also insignificant, which once again proves the applicability of extraordinary brick bond types along with traditional ones. 


\section{Discussion}

The proof of the extraordinary brick bond types applicability along with traditional ones is of great practical importance. It opens up many opportunities for project designers. The presence of an expanded variety of brick bond types gives the project designer the opportunity to choose: now the system that is most suitable and rational in certain conditions can be selected since specific aspects of building process and construction design features require brickwork with particular properties and to satisfy these needs it is necessary to choose the most effective bond system in these circumstances. The proper choice will not only decrease material resources consumption, but also reduce labor inputs and improve the construction quality.

The data obtained makes it possible to use extraordinary brick bond types in projects. The applying of these types decorates the urban environment architectural look. It is especially relevant for Russia where almost all façades lack basic decoration and aesthetic diversity. But boring and monotonous architectural environment is defective and offbalance. A person living in such environment experiences negative influences [19]. Apparently new original brickwork patterns are able to add the necessary artistic diversity and thereby the urban architectural environment can get advanced auspicious look.

This paper sets the direction for future research. Since only 16 brick bond types were considered in the framework of this paper, a huge number of existing bond systems were ignored. By analyzing the full diversity of bond types it will be possible to create an extensive database of information to assist in the construction design. Also the analysis mechanism itself needs to be improved to provide more complete information. So the improvement of this mechanism is also the subject of future research.

\section{Conclusions}

To sum up, in this paper 8 traditional and 8 extraordinary brick bond types were selected taking into account their entire existing diversity. The paper considered all the fundamental brickwork characteristics that affect the possibility of applying these types to a construction and affect the final cost of a brickwork cubic meter. The characteristics which values are not the same for all types were considered thoroughly.

Eventually the following results were obtained. The use of extraordinary brick bond types along with traditional ones is rational and effective. The argument is based on definite constructional, technological and economic facts obtained during the research. In some cases, the use of extraordinary brick bond types is even more rational and more profitable than the use of traditional ones, because there is an opportunity to choose unique brickwork design which characteristics are better than traditional bond types parameters. Opting for extraordinary brick bond types it becomes possible to decrease the mortar purchasing cost, reduce labour inputs for brickwork cubic meter, increase the compressive strength of construction and also advance the masonry stability in rest

\section{References}

1. J. Fiala, M. Mikolas, K. Krejsova, IOP Conf. Series: EES, 221: 012139 (2019)

2. J. Fiala, J. Fiala jr., M. Mikolas, IOP Conf. Series: EES, 362: 012164 (2019)

3. K. Pauwels, R. D’Aveni, JAMS, 44(1), 46-65 (2014)

4. W.R. Craig, NJ Studies: An Interdiscipl. J., 5(2), 57-124 (2019)

5. P. Medvedev, P. Gaidukov, E. Pugach, IOP Conf. Series: MSE, 471(2):022035 (2019) 
6. A. Chatterjee, Interstices: J.of Archit.and Related Arts, 18 (2017)

7. M.A. Hann, I.S. Moxon, Patterns: Design and Composition (Routledge, NY, 2018)

8. N. Valibeig, H. Mohammadi, NNJ, 18(2), (2016)

9. S.B. Singh, P. Munjal, J. of Building Engineering, 9, 10-16 (2017)

10. M. Como, Statics of Historic Masonry Constructions (Springer, 2013)

11. X. Palios, M.N. Fardis, E. Strepelias, S.N. Bousias, Engineering Structures, 131, 614624 (2016)

12. J. Springfield, Practice Period.on Struct. Des. and Constr., 17(1), 3-4 (2012)

13. P. Sloane, J. of Architectural Conservation, 18(2), 23-40 (2012)

14. R. Bartschi, T. Bonwetsch, M. Knauss, F. Gramazio, Adv. in Architectural Geometry, 137-147 (2010)

15. M.V.S. Cavalcanti, A.M.X. Francisco, D.M. Rodrigues, D.G. Silva, IBRACON Struct. and Mat. J., 11(7), 115-134 (2018)

16. S. Rajabzadeh, M. Sassone, NNJ, 19(1), 5-25 (2017)

17. F. Ceroni, G. Ernesto, G. Felice, M. Malena, Mat. and Structures, 47(12), (2014)

18. K.J. Ufere, Z. Zakka, G.U. Aliagha, B. Alias, Mediter. J. of SS, 6(4), 171-177 (2015)

19. O.A. Rastyapina, N.V. Korosteleva, IOP Conf. Series: MSE, 463(2):022010 (2018) 